\title{
Prevalence of antenatal depression and associated factors among pregnant women in Aneded woreda, North West Ethiopia: a community based cross-sectional study
}

\author{
Abebe Habtamu Belete ${ }^{1 *}$, Mulunesh Alemayehu Assega ${ }^{1}$, Amanuel Alemu Abajobir ${ }^{1,3}$, Yihalem Abebe Belay ${ }^{1}$ \\ and Mengistie Kassahun Tariku²
}

\begin{abstract}
Objectives: To assess the prevalence of antenatal depression and factors associated with antenatal depression among pregnant women in Aneded woreda, Northwest Ethiopia, 2019. A community based- cross sectional study was conducted in Aneded woreda among 7 kebles' of North-West, Ethiopia from March 16 to April 23, 2019. A total of 342 pregnant women were recruited using simple random sampling.

Result: The prevalence of antenatal depression was 15.20\%. Urban residence $[A O R=6.8 ; 95 \% \mathrm{Cl}(1.97,23.32)]$, marital status of being unmarried $[\mathrm{AOR}=5.1 ; 95 \% \mathrm{Cl}(1.79,14.63)]$, occupation of being government employee $[\mathrm{AOR}=8.8$; $95 \% \mathrm{Cl}(2.06,37.12)]$ and merchant $[\mathrm{AOR}=3.7 ; 95 \% \mathrm{Cl}(1.27,10.91)]$, prim gravid $[\mathrm{AOR}=5.3 ; 95 \% \mathrm{Cl}(2.03,13.82)]$, not attend $\mathrm{ANC}$ follow up $[\mathrm{AOR}=8.7 ; 95 \% \mathrm{Cl}(3.46,21.79)]$, intimate partner violence $[\mathrm{AOR}=4.5 ; 95 \% \mathrm{Cl}(1.28,15.52)]$, unplanned pregnancy $[\mathrm{AOR}=6.2 ; 95 \% \mathrm{Cl}(2.37,16.06)]$, and substance use $[\mathrm{AOR}=5.6 ; 95 \% \mathrm{Cl}(2.12,14.92)]$ were significantly factors. Strengthen the risk prevention activities so important to tackle the problem of antenatal depression.
\end{abstract}

Keywords: Prevalence, Antenatal depression, Pregnant women, Ethiopia

\section{Introduction}

Antenatal depression is a type of depression that can be occurred during pregnancy [1]. The World Health Organization (WHO) estimates that by the year 2020, depression will be the second greatest cause of disease burden in both sexes and in pregnant women takes the lion's share [2].

Currently, depression is considered to be a serious public health concern in the developing world that hinders maternal health improvement and is predicted to become the most common cause of disability [3].

Globally, $10 \%$ of pregnant women experience antenatal depression. In developing countries, antenatal depression is higher; it reaches up to $15.6 \%$ [4]. The prevalence

\footnotetext{
*Correspondence: abebeh2020@gmail.com

1 Department of Public Health, College of Health Sciences, Debre Markos University, Debre Markos, Ethiopia

Full list of author information is available at the end of the article
}

of antenatal depression varies within sub-Sahara African countries from $47 \%$ in rural South Africa to $9.9 \%$ in Ghana. Pregnant women living in low and middle income countries are known to be highly risk for antenatal depression [5, 6].

In Ethiopia, depression is the top ten most leading cause of diseases burden [7] and antenatal depression affects as many as one in three pregnant women; almost half of those affected by depression have thoughts of ending their life $[4,8]$.

Antenatal depression is associated with adverse obstetric and fetal outcomes, including low birth weight [9], intrauterine growth restriction of fetus and preterm deliveries [10]. Antenatal depression contribute to maternal morbidity and mortality, in terms of poor health, increased disability and prolonged labor $[10,11]$.

The commonly identified risk factors of antenatal depression include mother's age, education, employment 
status, marital status, substance use, pregnancy planned or not, parity and gravidity. Also intimate partner violence, gestational age, social support, low-income, and a history of antenatal care follow up were found to be the risk factors for antenatal depression [9, 10, 12-14].

The government of Ethiopia implements a mental health strategy of 2012/2013-2015/2016 which aimed to provide mental health services at all levels of the existing health system. The latest Health Sector Development Program (HSDP-IV) has set a target for integration of mental health into $50 \%$ of the healthcare settings by the end of the HSDP-IV in 2015 [12, 15].

Despite high concern of the government on maternal mental health, antenatal depression is a neglected issue in healthcare systems and remains a low priority in Ethiopian societies by different reasons. Previous studies had been focused on institutional based settings among antenatal care follow up pregnant women, but it is important to study the prevalence of antenatal depression and associated factors in population-based settings. Therefore, this research tried to assess the prevalence and factors associated with antenatal depression among pregnant women in Aneded woreda, Northwest Ethiopia.

\section{Main text \\ Methods \\ Study setting and period}

A community based cross-sectional study was conducted from March 16 to April 23, 2019 at Aneded woreda in Amhara Region, Ethiopia. It is located $18 \mathrm{~km}$ far away from Debre Markos town, $278 \mathrm{~km}$ from Addis Ababa, the capital city of Ethiopia and $260 \mathrm{~km}$ away from Bahir Dar the town of Amhara regional state.

The woreda has total populations of 110,326 total, 27,549 reproductive age groups and 3526 pregnant women. It has 19 rural and three urban kebeles, and there are 20 health posts and four health centers in the woreda [16].

\section{Sample size and sampling techniques}

Single population proportion was used to estimate the required sample size. It was calculated by assumption of $11.8 \%$ prevalence of antenatal depression in Debre Tabor [17], $95 \%$ of confidence interval, and $10 \%$ non-response rate. The total sample size was 162 . Then adding design effect of two to reduce the variability it becomes 356 .

Therefore, the final sample size was 356 . The sample size was proportionally allocated for seven kebeles based on the number of pregnant women. Households with registered pregnant women in community health information system were selected by simple random sampling technique.

\section{Measurement}

The data collection tool comprised a structured face to face interviewer administered pretested questionnaire and the translated Amharic version of the Beck Depression Inventory (BDI-II) scale was used to detect depression. It is a reliable and valid measure of depression used and has been validated for use during pregnancy in different countries and settings including Ethiopia [10, 18, 19]. It consists of 21 items; each item describes a specific symptom of depression. Each statement scored on a 4-point scale ( 0 to 3 ) and total score obtained by summing the ratings for each statement. Therefore, the total score ranges from 0 to 63 [20-22]. Pregnant women with a score of less than 16 were considered as normal while women with BDI score of 16 and above considered as depressed [19]. All factors related questions were used to assess characteristics of study participants during pregnancy whereas substance use related questions were used to assess ever use of substance.

Training was given for data collectors and supervisors. Regular supervision and immediate feedback were carried out daily by the principal investigator on the data collection period.

\section{Statistical analysis}

Collected data were coded and entered by epi data version 3.1, and then it was exported to STATA version 14.1 for analysis. Descriptive statistics were used to describe categorical variables. Bi-variable analyses were done and all variables were entered into the multivariable regression model. Independent variables with a P-value $<0.05$ with $95 \%$ confidence interval identified as statistically significant factors.

\section{Results}

The median age of pregnant women was 24 years with interquartile range of 18 to 28 years.

\section{Prevalence and factors associated with antenatal depression} In this study, the prevalence of antenatal depression was $15.20 \%$ (Table 1).

The study revealed that occupation of pregnant women had a significant association with antenatal depression in which the odd of depression was 8.8 times higher among government employees [AOR $=8.8$; 95\% CI $(2.06,37.12)]$ and 3.7 times higher among merchants $[\mathrm{AOR}=3.7 ; 95 \%$ CI $(1.27,10.91)]$ as compared to housewives. Pregnant women who had lived in urban areas were 6.8 times $[\mathrm{AOR}=6.8,95 \% \mathrm{CI}(1.97,23.32)]$ more likely depressed as compared to pregnant women who had lived in rural areas (Table 2).

Prim gravid women were 5.3 times $[\mathrm{AOR}=5.3,95 \% \mathrm{CI}$ $(2.03,13.82)]$ more likely to be depressed as compared 
Table 1 Characteristics of pregnant women related to in Aneded woreda, Northwest Ethiopia, 2019 ( $N=342)$

\begin{tabular}{|c|c|c|c|}
\hline Characteristics & Category & Frequency & Percent \\
\hline \multirow[t]{3}{*}{ Age } & $15-19$ & 108 & 31.58 \\
\hline & $20-29$ & 184 & 53.80 \\
\hline & $\geq 30$ & 50 & 14.62 \\
\hline \multirow[t]{3}{*}{ Occupation } & Housewife & 248 & 72.51 \\
\hline & Government employee & 28 & 8.19 \\
\hline & Merchant & 66 & 19.30 \\
\hline \multirow[t]{2}{*}{ Residence } & Urban & 27 & 7.89 \\
\hline & Rural & 315 & 92.11 \\
\hline \multirow[t]{2}{*}{ Marital status } & Unmarried** & 31 & 9.06 \\
\hline & Married & 311 & 90.94 \\
\hline \multirow[t]{5}{*}{ Wealth index } & Poorest & 76 & 22.2 \\
\hline & Poor & 97 & 28.36 \\
\hline & Middle & 57 & 16.67 \\
\hline & Richer & 86 & 25.15 \\
\hline & Richest & 26 & 7.60 \\
\hline \multirow[t]{2}{*}{ Gravidity } & Prim gravid & 83 & 24.27 \\
\hline & Multi gravid & 259 & 75.73 \\
\hline \multirow[t]{2}{*}{ Pregnancy planed } & Yes & 264 & 77.19 \\
\hline & No & 78 & 22.81 \\
\hline \multirow[t]{2}{*}{ ANC follow up } & Yes & 259 & 75.73 \\
\hline & No & 83 & 24.27 \\
\hline \multirow{2}{*}{$\begin{array}{l}\text { Intimate partner } \\
\text { violence }\end{array}$} & Yes & 24 & 7.02 \\
\hline & No & 318 & 92.98 \\
\hline \multirow[t]{2}{*}{ substance use } & Yes & 53 & 15.49 \\
\hline & No & 289 & 84.5 \\
\hline
\end{tabular}

*Statisically significance $(P<0.05)$

**Single, divorced and widowed

to women with who had history of previous pregnancy. Pregnant women who had not planned their current pregnancy were 6.2 times $[\mathrm{AOR}=6.2,95 \% \mathrm{CI}(2.37$, 16.06)] more likely to have antenatal depression than those women of who planned their current pregnancy (Table 2).

Women who had not ANC follow up were 8.7 times $[\mathrm{AOR}=8.7,95 \% \mathrm{CI}(3.46,21.79)]$ at higher odds to develop depression as compared to with those pregnant women who have had antenatal care follow up (Table 2).

The odds ratio revealed that those pregnant women who have suffered intimate partner violence were 4.5 times $[\mathrm{AOR}=4.5,95 \% \mathrm{CI}(1.28,15.52)]$ more likely to experience depression during their pregnancy than those pregnant women of without this history (Table 2).

\section{Discussion}

The prevalence of antenatal depression was $15.20 \%$ [(95\% CI $(11.57,19.46)]$.
The finding was consistent with a study done in Debre Tabor town (11.8\%) [17], in Dubti Hospital Northeast Ethiopia (17.9\%) [10], in South Asians (17.5\%) [23], at Khartoum maternity hospital in Sudan (13.4\%) [24], and in State of South Minas Gerais, Brazil (14.8\%) [25] and lower than the findings from Gondar university hospital, Northwest Ethiopia (23\%) [18], Maichew town, North Ethiopia (31.1\%) [6], Adama (31.2\%) [19], Shashemane (25.6\%) [26], Addis Ababa, Ethiopia (24.94\%) [27], Mombasa, Kenya (20\%) [28], Nairobi, Kenya (32.9) [8], Nigeria (24.5\%) [29], Western Saudi Arabia (57.5\%) [25], India (36.75\%) [30], Pakistan (18-80\%) [31], Karachi, Pakistan (81\%) [32] and Middle Easterners (19.5\%) [33].

In other way, the current finding was higher than study done in Western Europeans (8.6\%) [33].

The difference might be due to socio demographic, socio economic and cultural variations.

Moreover, this study also identified factors that have association with antenatal depression and found that residence in urban, occupation of being government employee and merchant, marital status of being unmarried, prim gravidity, unplanned pregnancy, not attend antenatal care follow up, intimate partner violence, and psychoactive substance use were factors that had significantly associated with antenatal depression.

Being government employee and merchant in this study, compared to being house wife was associated with depression, which increases the odds of endorsing depression during pregnancy by nine and four times respectively. This is different from the study done in Gondar university hospital, Northwest Ethiopia [18]. This difference could be pregnant women of government employee in this study area engage in triple burden duties as they are working to support their families with work outside their homes, at the same time carrying full responsibility for childcare and government employer. And also, those government employers are paid the minimum Ethiopian monthly wage which leads to unable cope up with the current economic inflation including the baby dipper cost, milk, house rent, social payment and consumable foods. Pregnant women of merchant due to fear of decreasing their income after delivery lead to difficulties in managing their household food security.

The prevalence of antenatal depression was seven times higher among women living in urban areas than those living in rural areas. The possible explanation for this finding might be the risk factors for antenatal depression that were unequally distributed across geographic areas and currently in urban areas social capital is loose. Fear of downhill and mostly economic inflation are the major responsible conditional situations that lead depression in urban area. 
Table 2 Bi-variable and multivariable analyses result of antenatal depression among pregnant women in Aneded woreda, 2019

\begin{tabular}{|c|c|c|c|c|c|}
\hline \multirow[t]{2}{*}{ Variables } & \multicolumn{2}{|c|}{ Antenatal depression } & \multirow[t]{2}{*}{ COR $(95 \% \mathrm{Cl})$} & \multirow[t]{2}{*}{ AOR $(95 \% \mathrm{Cl})$} & \multirow[t]{2}{*}{ P-value } \\
\hline & Depressed & Normal & & & \\
\hline \multicolumn{6}{|l|}{ Age in year } \\
\hline $15-19$ & 25 & 83 & 1 & 1 & 0.06 \\
\hline $20-29$ & 24 & 160 & $0.5(0.25,0.93)$ & $0.6(0.21,1.44)$ & 0.22 \\
\hline$\geq 30$ & 3 & 47 & $0.2(0.06,0.74)$ & $0.2(0.02,1.25)$ & 0.08 \\
\hline \multicolumn{6}{|l|}{ Occupation status } \\
\hline House wife & 28 & 220 & 1 & & \\
\hline Government employee & 11 & 17 & $5.1(2.2,11.9)$ & $8.8(2.06,34.40)^{*}$ & 0.001 \\
\hline Merchant & 13 & 53 & $1.9(0.94,3.97)$ & $3.7(1.27,10.91)^{*}$ & 0.01 \\
\hline \multicolumn{6}{|l|}{ Residence } \\
\hline Urban & 12 & 15 & $5.5(2.4,12.6)$ & $6.8(1.97,23.32)^{*}$ & 0.001 \\
\hline Rural & 40 & 275 & 1 & & \\
\hline \multicolumn{6}{|l|}{ Marital status } \\
\hline Unmarried** & 14 & 17 & $5.9(2.7,12.97)$ & $5.1(1.79,14.63)^{*}$ & 0.001 \\
\hline Married & 38 & 273 & 1 & & \\
\hline \multicolumn{6}{|l|}{ Wealth index } \\
\hline Poorest & 5 & 71 & $0.2(0.10,0.62)$ & $0.1(0.07,1.23)$ & 0.12 \\
\hline Poor & 9 & 88 & $0.3(0.13,0.52)$ & $0.2(0.14,1.57)$ & 0.09 \\
\hline Middle & 3 & 54 & $0.1(0.04,0.63)$ & $0.09(0.05,1.08)$ & 0.07 \\
\hline Rich & 35 & 77 & 1 & 1 & 0.15 \\
\hline \multicolumn{6}{|l|}{ Gravidity } \\
\hline Yes & 20 & 239 & 1 & & \\
\hline No & 32 & 51 & $7.5(3.97,14.2)$ & $5.3(2.03,13.82)^{*}$ & 0.001 \\
\hline \multicolumn{6}{|l|}{ Pregnancy planning } \\
\hline Yes & 28 & 236 & 1 & & \\
\hline No & 24 & 54 & $3.75(2.02,6.97)$ & $6.2(2.37,16.06)^{*}$ & 0.001 \\
\hline \multicolumn{6}{|l|}{ ANC follow up } \\
\hline Yes & 21 & 238 & 1 & & \\
\hline No & 31 & 52 & $6.76(3.6,12.7)$ & $8.7(3.46,21.79)^{*}$ & 0.001 \\
\hline \multicolumn{6}{|l|}{ IPV } \\
\hline Yes & 13 & 11 & $8.46(3.54,20.2)$ & $4.5(1.28,15.52)^{*}$ & 0.01 \\
\hline No & 39 & 279 & 1 & & \\
\hline \multicolumn{6}{|l|}{ Substance use } \\
\hline Yes & 25 & 28 & $8.7(4.44,16.92)$ & $5.6(2.12,14.92)^{*}$ & 0.001 \\
\hline No & 27 & 262 & 1 & & \\
\hline
\end{tabular}

*Statisically significance $(P<0.05)$

**Single, divorced and widowed

Unmarried women were five times more likely to have antenatal depression as compared to those women who had married. Similar finding was reported from other studies $[6,26]$. This might be explained that no social support, poor financial capacity, culture of unmarried mother and psychological issues may in turn contribute to antenatal depression.

Prim gravid women were five times more likely to be depressed as compared to those of multi gravid. This finding is consistent with a study done in Gondar university hospital, Northwest Ethiopia [18]. This might be prim gravid women have not previous pregnancy experience; fear of childbirth and responsibility of child care is more common among primigravid which could aggravate the occurrence of depression.

Pregnant women who did not plan their current pregnancy were six times more likely to develop antenatal depression as compared with pregnant women who planned their current pregnancy. This finding is consistent with a study done in Addis Ababa [27], in Debre 
Tabor town, Northwest Ethiopia [17]. This might be due to women who did not plan their current pregnancy were getting into additional family burden, may have another imminent plan and it may be source of conflict in the household that leads to antenatal depression.

Pregnant women who were not attending ANC follow up were nine times more likely to develop antenatal depression as compared to pregnant women who were attending ANC follow up services. This finding is consistent with a study done in Gondar university hospital, Northwest Ethiopia [18]. It is possible that mothers who had ANC follow up have a better chance to get information about pregnancy preparedness and how to avert risk factors.

The odds ratio revealed that pregnant women who have suffered intimate partner violence were four times more likely to experience depression during pregnancy than those without this history. This finding is consistent with a study done in state of South Minas Gerais, Brazil [34]. This might be due to women fear of divorce, victims feeling of guilt and shame which is an aggravating factor that contributes to the occurrence of depression.

Pregnant women who had history of intake psychoactive substance were 6 times more likely to experience antenatal depression than those who were not intake psychoactive substance. This finding is consistent with a study done in Nigeria in 2016 [29]. This might be psychoactive substance like alcohol is a depressant. So, any amount of intake during pregnancy can lead to depression.

\section{Conclusions}

More than one in six pregnant women had depression. Attending ANC during their pregnancy, conduct pregnant women husband conversion on the importance of intimate partner support and family planning services should be strengthened to avoid unplanned pregnancy. Therefore, considering antenatal depression as one component of antenatal care service and strengthen the risk prevention activities need crucial attention.

\section{Limitation of the study}

Due to stigma towards mental illness, some participants might not actually report what they feel. It might incur social desirability bias.

\section{Abbreviations}

ANC: antenatal care; BDI: Beck Depression Inventory; CMD: common mental disorder; EPDS: Edinburg Postnatal Depression Scale; IPV: intimate partner violence; MCH: maternal and child health; ROC: receiver operator characteristics; SDG: Sustainable Development Goal; WHO: World Health Organization.

\section{Acknowledgements}

We would like to acknowledge Debre Markos University, College of Health Sciences, and Department of Public Health.

Our sincere and deepest gratitude would go to Amhara national regional state health bureau (ANRHB) and Aneded district health office for funding the research.

It is also glad to thank data collectors, supervisors and the study participants.

\section{Authors' contributions}

AH wrote the proposal, involved in study design, analyzed the data, drafted paper. MA approved the design, the proposal and reviewing the manuscript. AA involved in data analysis, revised subsequent drafts of the paper and reviewing of the manuscript. YA revised subsequent drafts of the paper and reviewing of the manuscript. MK involved data analysis and reviewing the manuscript. All authors read and approved the final manuscript.

\section{Funding}

AH received funding from Amhara national regional state health bureau (ANRHB) and Aneded district health office for data collection. The funders had no role in study design, data analysis, decision to publish and preparation of the manuscript.

\section{Availability of data and materials}

The data sets generated during the current study are available from corresponding author on reasonable request.

\section{Ethics approval and consent to participate}

Ethical clearance was obtained from Ethical Review Committee of Debre Markos University Health Science College. Permission was obtained from local authorities and concerned government officials. A support letter was written to each selected kebele and informed written consent was received from each study subjects. Informed written consent was also obtained from a parent or guardian on behalf of the participants under the age of 18 years. Respondents were interviewed in a separate room whenever asked the questionnaires to keep their privacy. Anyone who was not willing to take part in the study had the full right to do so. Finally, women screened with antenatal depression were referred to their nearest public health facility coordinating with health extension workers.

Consent for publications

Not applicable.

\section{Competing interest}

The authors declare that they have no competing interests.

\section{Author details \\ ${ }^{1}$ Department of Public Health, College of Health Sciences, Debre Markos University, Debre Markos, Ethiopia. ${ }^{2}$ Department of Public Health, College of Medicine and Health Sciences, Bahir Dar University, Bahir Dar, Ethiopia. ${ }^{3}$ Maternal and Child Wellbeing Unit, African Population and Health Research Centre, Nairobi, Kenya.}

Received: 2 September 2019 Accepted: 10 October 2019

Published online: 30 October 2019

\section{References}

1. Austin M-P. Highest N and the Expert Working Group. Mental health care in the perinatal period: Australian clinical practice guideline. Centre of perinatal excellence depression during pregnancy. 2017.

2. World Health Organization. The global burden of disease. http://www. ispnpsych.org/docs/4-00Global-Burden.pdf. Accessed 20 Apr 2019.

3. African Union. Status report on maternal newborn child and adolescent health: focusing on unfinished business in Africa. Second session of the specialized technical committee on health, population and drug control (Stc-Hpdc-2) Addis Ababa, Ethiopia. 2017.

4. World Health Organization. Depression and other common mental disorders: global health estimates. Geneva: World Health Organization; 2017. 
5. Jean T, Tomlinson M, Stein A, Bar T. The prevalence and clinical presentation of antenatal depression in rural South Africa. S Afr Med J. 2012;102(12):362-73.

6. Mossie TB, Sibhatu AK, Dargie A, Ayele AD. Prevalence of antenatal depressive symptoms and associated factors among pregnant women in Maichew, North Ethiopia: an institution based study. Ethiop J Health Sci. 2017;27(1):59-66. https://doi.org/10.4314/ejhs.v27i1.8.

7. Weobong B, Soremekum S, Ten Asbroek AH, Amenga S, et al. Prevalence and determinant of antenatal depression among pregnant women in a predominantly rural population in Ghana: The DON population based study. J Affect Disord. 2014;165:1-7.

8. Osok J, Kigamwa P, Vander Stoep A, Huang KY, Kumar M. Depression and its psychosocial risk factors in pregnant Kenyan adolescents: a cross sectional study in a community health centre of Nairobi. BMC Psychiatry. 2018;18:136. https://doi.org/10.1186/s12888-018-1706.

9. Baumgartner JN, Parcesepe A, Mekuria YG, Abitew DB, Gebeyehu W, Okello F, et al. Maternal mental health in Amhara region, Ethiopia: a cross-sectional survey. Glob Health Sci Pract. 2014;2(4):482-6. https://doi. org/10.9745/GHSP-D-14-00119.

10. Belay YA, Moges NA, Hiksa FF, Arado KK. Prevalence of antenatal depression and associated factors among pregnant women attending antenatal care at Dubti Hospital: a case of pastoralist region in Northeast Ethiopia. Depress Res Treat. 2018. https://doi.org/10.1155/2018/1659089.

11. Tefera TB, Erena AN, Kuti KA, Hussen MA. Perinatal depression and associated factors among reproductive aged group women at Goba and Robe Town of Bale Zone, Oromia Region, Southeast Ethiopia; cross sectional study design. Matern Health Neonatol Perinatol. 2015;1:12.

12. Federal Democratic Republic of Ethiopia Ministry of Health: National Mental Health Strategy 2012/2013-2015/2016.

13. Prince M, Alem A, Kebede D, Stewart R, Mogga S, et al. Outcome of major depression in Ethiopia: population-based study. Br J Psychiatry. 2006;189(3):241-6.

14. Getinet W, Amare T, Boru B, Shumet S, Worku W, Azale T. Prevalence and risk factors for antenatal depression in Ethiopia: systematic review. Depress Res Treat. 2018. https://doi.org/10.1155/2018/3649269.

15. Federal Ministry of Health. Health sector development program IV 2010/11-2014/15. Addis Ababa: Federal Ministry of Health; 2010.

16. Plan department, Aneded district health office annual plan and fourth quarter, 2018 report.

17. Bisetegn TA, Mihretie G, Muche T. Prevalence and predictors of depression among pregnant women in Debre tabor Town, Northwest Ethiopia. PLoS ONE. 2016. https://doi.org/10.1371/journal.pone.0161108.

18. Biratu A, Haile D. Prevalence of antenatal depression and associated factors among pregnant women in Addis Ababa, Ethiopia: a cross-sectional study. Reprod Health. 2015;12:99.

19. Ayele TA, Azale T, Alemu K, Abdissa Z, Mulat H, Fekadu A. Prevalence and associated factors of antenatal depression among women attending antenatal care service at Gondar university hospital, Northwest Ethiopia. PLoS ONE. 2016;11(15):e0155125.

20. Sahile MA, Segni MT, Awoke T, Bekele D. and predictors of antenatal depressive symptoms among women attending Adama hospital antenatal clinic, Adama, Ethiopia: hospital based cross sectional study. Int J Nurs Midwifery. 2017;9(5):58-64. https://doi.org/10.5897/JNNM2016.0239.
21. Beck AT, Steer RA, Brown GK. Beck depression inventory. http://pears onassess.com/HAIWEB/Cultures/en-us/default. Accessed 22 Apr 2019

22. Kneipp SM, Kairalla JA, Stacciarini J, Pereira D. The Beck depression inventory II factor structure among low-income women. Nurs Res. 2009:58(6):400-9.

23. Smarr KL, Keefer AL. Measures of depression and depressive symptoms: Beck depression inventory-II (BDI-II), center for epidemiologic studies depression scale (CES-D), geriatric depression scale (GDS), hospital anxiety and depression scale (hads), and patient health questionnaire9(PHQ-9). Arthritis Care Res. 2011;63(S11):454-66.

24. Roomruangwong C, Epperson CN. Perinatal depression in Asian women: prevalence, associated factors, and cultural aspects. Asian Biomed. 2011;5(2):179-93

25. Handady SO, Sakin HH, Ahmed KYM, Alawad AAM. Prevalence of antenatal depression among pregnant women in Khartoum maternity hospital in Sudan. Am J Psychol Behav Sci. 2015;2(4):141-5.

26. Bawahab JA, Alahmadi JR, Ibrahim AM. Prevalence and determinants of antenatal depression among women attending primary health care centers in Western Saudi Arabia. Saudi Med J. 2017;38(12):1237-42.

27. Gemta A, John Snow Inc. Prevalence and factors associated with antenatal depression among women following antenatal care at Shashemane health facilities, South Ethiopian. Ann Glob Health. 2015. https://doi. org/10.1016/j.aogh.2015.02.709.

28. Mukherjee I, Notia A, Alavi Z, Tomenson B, Hawa F, Husain N, et al. Prevalence of common mental disorders and its association with life events and social support in mothers attending a well-child clinic: findings from Mombasa, Kenya. SAGE Open. 2016. https://doi.org/10.1177/2158244016 677324.

29. Thompson O, Ajayi I. Prevalence of antenatal depression and associated risk factors among pregnant women attending antenatal clinics in Abeokuta North local government area, Nigeria. Depress Res Treat. 2016;2016:4518979. https://doi.org/10.1155/2016/4518979.

30. Hegde Shruthi S, Pai Keshava K, Abhishekh Hulegar A, Sandeep KR. Prevalence of antenatal depression and gender preference: a cross sectional study among Mangalore population, Karnataka, India. J Pharm Biomed Sci. 2013;29(29):1011-4 (Article no 19)

31. Saeed $A$, Humayun A, Raana T. The alarming rise in prevalence of antenatal depression in Pakistan: a review. Proc SZPGMI. 2016;30(2):107-11.

32. Jafri SAM, Ali M, Ali R, Shaikh S, Abid M, et al. Prevalence of depression among pregnant women attending antenatal clinics in Pakistan. Acta Psychopathol. 2017;3:5-54.

33. Eberhard-Gran M, Sletner L, Slinning K, Martinsen EW, Holme I, Shakeel N, et al. A prospective cohort study of depression in pregnancy, prevalence and risk factors in a multi-ethnic population. BMC Pregnancy Childbirth. 2015;15:5.

34. Silva MMJ, Leite EPRC, Nogueira DA, Clapis MJ. Depression in pregnancy. Prevalence and associated factors. Invest Educ Enferm. 2016:34(2):342-50.

\section{Publisher's Note}

Springer Nature remains neutral with regard to jurisdictional claims in published maps and institutional affiliations.

Ready to submit your research? Choose BMC and benefit from

- fast, convenient online submission

- thorough peer review by experienced researchers in your field

- rapid publication on acceptance

- support for research data, including large and complex data types

- gold Open Access which fosters wider collaboration and increased citations

- maximum visibility for your research: over 100M website views per year

At BMC, research is always in progress.

Learn more biomedcentral.com/submissions 